\title{
Animasi Beladiri Judo Low Polygon Menggunakan Kinect
}

\author{
${ }^{1}$ Rizqi Nidzar Achmadi, ${ }^{2}$ Eko Budi Cahyono, ${ }^{3}$ Lailatul Husniah \\ Jurusan Teknik Informatika Universitas Muhammadiyah Malang \\ e-mail: ${ }^{1}$ rizqi.nidzar@gmail.com, ${ }^{2}$ ekobudi@umm.ac.id, ${ }^{3}$ husniah@umm.ac.id
}

\begin{abstract}
Abstrak
Animasi merupakan sebuah proses yang dilakukan untuk menghiupkan sebuah benda mati melalui proses ilusi gerakan dari gambar statis yang dilakukan sedikit demi sedikit hingga memiliki kesan benda mati tersebut hidup. Penelitian ini dilakukan dengan tujuan menganimasikan gerakan bantingan beladiri Judo dengan menggunakan model 3D Low Polygon. Proses animasi menggunakan 2 kamera Kinect $v 1$ yang diposisikan dengan sudut $60-90^{\circ}$ dan posisi kamera $180^{\circ}$ terhadap aktor. Gerakan animasi motion capture memiliki ketidakakuratan pada posisi kamera $60-90^{\circ}$ terhadap aktor. Hasil gerakan animasi motion capture dengan posisi kamera $180^{\circ}$ terhadap aktor dapat diterapkan pada model 3D dengan hasil yang baik. Dengan penelitian ini diharapkan bisa menjadi acuan untuk perbaikan teknik motion capture gerakan bantingan beladiri Judo secara lebih baik.
\end{abstract}

Kata kunci: Judo, Animasi Low Polygon, Kinect Motion Capture

\begin{abstract}
Animation is a process that is carried out to blow an inanimate object through the illusion of movement from a static image that is done little by little until it has the impression that an inanimate object is alive. This research was conducted with the aim of animating Judo kickback movements using the 3D Low Polygon model. The animation process uses 2 Kinect $v 1$ cameras positioned at an angle of $60-90^{\circ}$ and camera position $180^{\circ}$ towards the actor. Motion capture motion animation has inaccuracies in the camera position 60-90 ${ }^{\circ}$ to the actor. The results of motion capture motion animation with a camera position of $180^{\circ}$ to the actor can be applied to $3 D$ models with good results. With this research it is hoped that it can become a reference for better improvements in the motion capture technique of Judo kickback movements.
\end{abstract}

Keywords: Judo, Low Polygon Animation, Kinect Motion Capture

\section{Pendahuluan}

Animasi berasal dari kata "to animate" dalam bahasa inggris yang memiliki arti menggerakan atau menghidupkan. Animasi merupakan sebuah proses untuk mendapatkan sebuah ilusi gerakan dari serangkaian gambar statis yang didefinisikan oleh Ibiz Fernandes dalam buku "Macromedia Flash Animation \& Cartooning: A creative Guide". Selain itu menggerakan suatu objek atau gambar yang diam juga diartikan sebuah animasi. Contohnya benda mati atau model 2D dan 3D yang digerakkan sedikit demi sedikit selama beberapa waktu sehingga memberikan kesan bahwa benda mati atau model tersebut hidup[1][2].

Pembuatan animasi 2D menggunakan beberapa teknik animasi diantaranya rotoscoping, keyframe stopmotion dan teknik yang lainnya. Pada animasi 3D, teknik untuk animasi bisa menggunakan teknik Motion Capture. Teknik motion capture diangap lebih mudah untuk dilakukan dibanding menggunakan teknik animasi lainnya karena gerakan yang didapat dan dihasilkan bisa lebih nyata. Salah satu alat yang digunakan untuk motion capture adalah Microsoft Kinect. Pada penelitian ini menggunakan Microsoft Kinect karena alat ini dapat melakukan motion cature tanpa marker dan memanfaatkan deeply camera. Mendapakan gerakan yang nyata dengan detail merupakan salah satu keuntungan yg didapat dari menggunnakan teknik motion capture[3]-[5].

Animasi dapat dimanfaatkan dalam berbagai bidang, salah satunya dimanfaatkan untuk pembelajaran. Anak-anak, remaja, bahkan dewasa pun tertarik dengan adanya animasi baik 
yang berupa film ataupun permainan. Pada tugas akhir ini, animasi dipilih dan digunakan sebagai media pembelajaran untuk menarik minat dan mengenal ilmu beladiri, khususnya beladiri Judo. [6]

Beladiri Judo merupakan perkembangan dari beladiri Jujutsu. Bantingan dan kuncian pada tubuh lawan merupakan fokus dalam beladiri ini meskipun Judo memiliki teknik menyerang lawan menggunakan tendangan, pukulan, bahkan menggunakan pedang atau pisau sebagai senjata untuk membeladiri. Judo berasal dari kata Ju yang berarti lembut atau halus dan Do yang berarti cara atau jalan. Beladiri Judo di Indonesia sudah dipertandingkan pada berbagai ajang pertandingan olahraga ditingkat kabupaten, provinsi, nasional dan bahkan internasional. Pada pertandingan beladiri Judo, para atlet Judo pemula menggunakan teknik bantingan yang mudah dilakukan dan mampu menjatuhkan lawan dengan cepat. Teknik yang biasa digunakan oleh atlet pemula bisa dengan mudah dipelajari. Beladiri Judo mulai berkembang di Indonesia pada tahun 1949 dan pada 25 Desember 1955 berdiri sebuah organisasi yang menaungi olahraga beladiri Judo yang diberi nama Persatuan Judo Seluruh Indonesia disingkat menjadi PJSI.

Judo merupakan beladiri yang belum banyak diketahui oleh masyarakat umum. Beladiri Judo adalah salah satu jenis beladiri wajib untuk seluruh anggota POLRI selain Tarung Derajat, karena teknik pada beladiri Judo bersifat melumpuhkan lawan. Judo memiliki banyak teknik bantingan, kuncian, patahan, dan serangan.

Pembelajaran teknik beladiri Judo selain didapat dari pelatih, juga bisa didapat dari buku pada penjual penjual buku meskipun dalam jumlah yang tidak banyak, dikarenakan jumlah yang terbatas atau memang tidak banyak penerbit buku yang menerbitkannya. Selain buku, pada video yang ada di internet jumlahnya sangat banyak dan tekniknya juga beragam, tetapi pada video yang ada di internet terkadang kurang menarik sehingga teknik beladiri Judo menjadi kurang dipahami. Melalui wawancara singkat yang pernah dilakukan oleh peneliti kepada pelatih beladiri Judo, ada 11 gerakan yang menurut pelatih bisa dipelajari dengan mudah oleh atlet pemula yaitu Ashi-Guruma, Ko-Soto-Gake, Ko-Soto-Gari, O-Soto-Gari, Uchi-Mata, Morote-Gari, Ippon-SeoiNage, Sukui-Nage, Hane-Goshi, Sode-Tsuri-Komi-Goshi, dan Uki-Goshi[7].

Pada penelitian sebelumnya, peneliti masih belum menemukan animasi untuk beladiri Judo dalam bentuk aplikasi, tetapi pada penelitian lain yang masih dalam lingkup animasi beladiri, Adi Susanto (2015) telah melakukan penelitian tentang perancangan aplikasi beladiri untuk beladiri Tapak Suci. Metode pertama yang digunakan pada pengambilan data, dilakukan dengan cara menyebar angket kepada anggota baru dan para pengurus di UKM beladiri Tapak Suci Universitas Muhammadiyah Malang dengan sampel 20 anggota. Metode kedua yang digunakan yaitu dengan wawancara terhadap narasumber yang ada di UKM Beladiri Tapak Suci Universitas Muhammadiyah Malang. Dari hasil angket dan wawancara dapat disimpulkan kebutuhan dari pengguna yang kemudian diimplementasikan dalam bentuk model 2D dan gerakan tapak suci menggunakan animasi key frame.

Penelitian lain yang didapati oleh peneliti adalah tentang motion capture yang digunakan dalam pembuatan animasi oleh Rini Setyowati (2016), pada penelitian tersebut dilakukan motion capture untuk game Story of Singosari dan hanya terbatas pada gerakan berjalan, melompat, berlari dan menyerang menggunakan 1 kamera Microsof Kinect[10]. Merujuk pada latar belakang penelitian yang telah dijelaskan diatas, pada penelitian ini akan dikembangkan animasi beladiri Judo ini dikembangkan pada sistem operasi Android menggunakan teknik animasi motion capture dan dikemas dalam bentuk aplikasi pada smartphone android, sehingga animasi ini kedepannya dapat menjadi panduan untuk mempelajari teknik beladiri Judo yang lebih menarik bagi para atlet pemula.

\section{Metode Penelitian}

Metode Media Development Life Cycle (MDLC) digunakan agar aplikasi yang dihasilkan menjadi lebih baik dan memiliki kualitas. Tahapan dari metode MDLC yaitu concept, design, material, collecting, testing, dan distribution. Tahapan tersebut tidak harus selalu berurutan, tetapi meskipun begitu tahap concept harus menjadi hal yang pertama dilakukan.

\subsection{Concept}

Tahap ini bertujuan untuk mengetahui siapa pengguna, dan menentukan tujuan pembuatan aplikasi. Pada penelitian ini pengguna adalah para atlet pemula karena mereka membutuhkan alat bantu untuk mengembangkan potensi mereka dalam berlatih beladiri judo.

\subsection{Design}

Tahap design merupakan tahapan yang dilakukan untuk pembuatan dan pengolahan spesifikasi yang meliputi arsitektur, gaya, tampilan, dan kebutuhan material lainnya. Tahap ini biasanya menggunakan story board untuk mendeskripsikan setiap scene.

REPOSITOR, Vol. 2, No. 10, Oktober 2020, Pp. 1429-1435 


\subsubsection{Struktur Menu} umum.

Struktur menu menggambarkan menu apa saja yang ada dalam aplikasi ini secara

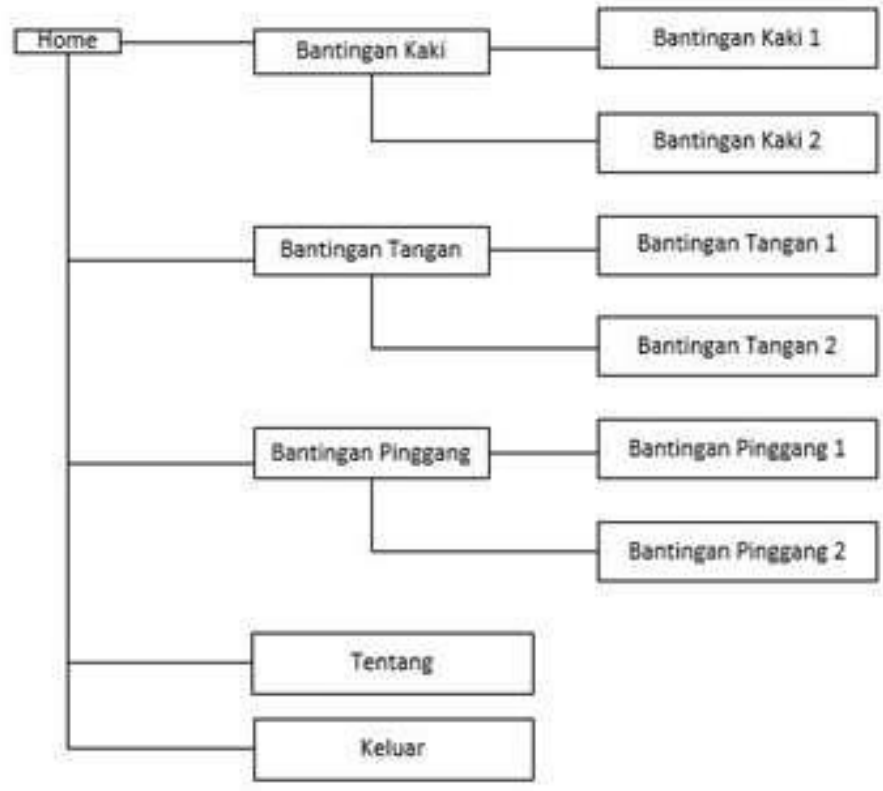

\subsubsection{Material Coleccting}

Gambar 1 Struktur Menu

Material Collecting merupakan bagian atau tahap pengumpulan bahan sesuai dengan kebutuhan yang akan dikerjakan pada proses pembuatan. Material yang dimaksud berupa model 3D low polygon, audio, gambar, dan lain-lain.

\subsubsection{Assembly}

Tahap ini adalah tahap pembuatan aplikasi atau bahan multimedia yang didasarkan pada tahapan design. Pada penelitian ini pembuatan animasi beladiri judo lowpolygon menggunakan software Blender, Unity 3D, dan iPi Mocap.

\subsubsection{Testing}

Tahap testing dilakukan untuk mengetahui apakah aplikasi atau program yg dibuat sudah sesuai, terdapat kesalahan atau tidak.pada tahap ini dilakukan pengujian dikalangan sendiri (alpha test) sebelum masuk ke tahap distribusi.

\subsubsection{Distribution}

Tahap distribution merupakan tahap dimana aplikasi akan disebar kepada umum dalam hal ini sebagai awal adalah atlet pemula, sehingga dapat dimanfaatkan sebagaimana tujuan awal pembuatan aplikasi.

\subsection{Tahapan Animasi}

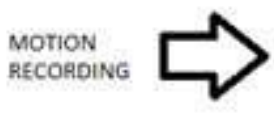

MOTION
RECOADIN TRACKING

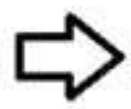

MOTION AETARGETTING

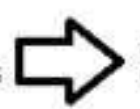

ANIMATED CHARACTER

\subsubsection{Motion Recording}

Gambar 2 Tahapan Animasi

Kinect menggunakan teknologi perekam gerakan tanpa tanda (Markerless Motion Capture)[3]-[5], [8]. Beberapa hal yang perlu diperhatikan saat akan melakukan motion recording

\section{: \\ - Mempersiapkan ruangan untuk kegiatan motion capture.}

- Menggunakan aktor yang memiliki fisik sehat / tidak cacat.

- Aktor menggunakan pakaian yang sesuai dengan bentuk tubuh akor (tidak menggunakan jaket tebal, rok, dan daster)

Berdiri dengan posisi T-Pose selama 1-2 deik sebagai inisialisasi kemudian melakukan gerakan inti. Posisi kamera Kinect adalah sebagai berikut : 


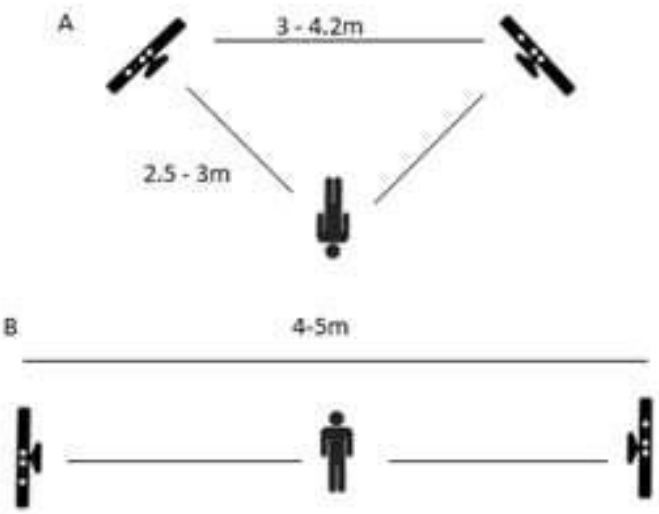

Gambar 3 Posisi Kamera Kinect

\subsubsection{Motion Tracking}

Hasil dari motion recording diolah menggunakan iPi Motion Capture untuk kemudian disesuaikan dengan berbagai kondisi pada model dengan kondisi gender dan bentuk tubuh. Lalu dilakukan tracking dan penghapusan jitter untuk menghilangkan noise atau gangguan. Setelah proses ini selesai maka file akan siap diekspor dengan format .fbx dan atau .bvh.

\subsubsection{Motion Retargeting}

Setelah proses motion tracking, animasi skeleton yang telah jadi kemudian digabung dengan karakter 3D yang akan dipakai untuk animasi tersebut menggunakan aplikasi Unity 3D. Hal yang perlu diperhatikan saat melakukan motion retargetting yaitu mode 3D memiliki kerangka pada tubuhnya. Keduanya disatukan dengan teknik mecanim yang kemudian model 3D tersebut akan bergerak seperti animasi yang diterapkan pada model tersebut.

\subsubsection{Skenario Pengujian}

Skenario Pengujian pada penelitian ini yaitu :

Pada posisi kamera 60 - $90^{\circ}$ terhadap aktor dilakukan percobaan merekam gerakan oleh aktor dan pada posisi kamera $180^{\circ}$ dilakukan percobaan merekam gerakan oleh aktor.

\section{Hasil Penelitian dan Pembahasan}

\subsection{Hasil Pengujian Posisi Kamera Kinect Terhadap Aktor}

Pengujian pertama yang dilakukan pada Tugas Akhir ini yaitu menempatkan 2 kamera Kinect dengan posisi $\mathrm{V} 60-90^{\circ}$ terhadap aktor dan pengujian kedua menempatkan 2 kamera Kinect dengan posisi $180^{\circ}$ (depan dan belakang) terhadap aktor[4].

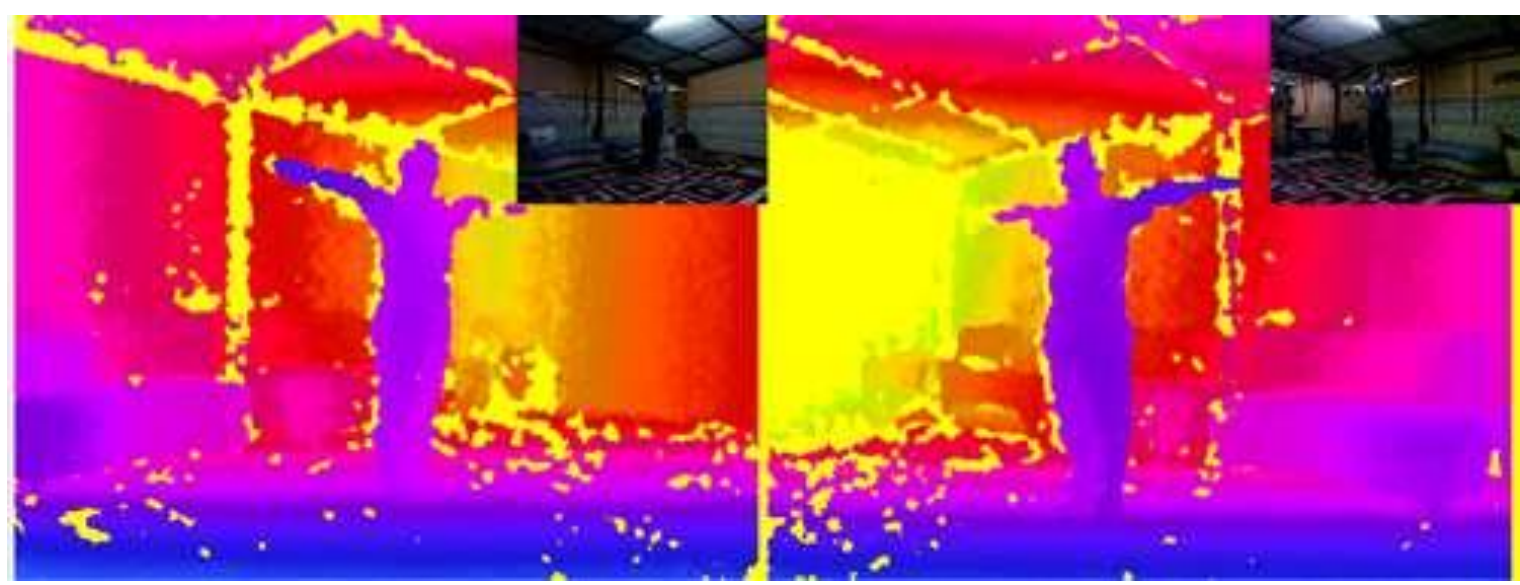

Gambar 4 Posisi Kamera Kinect Dengan Sudut 60-90

Pada Gambar 4 tersebut kamera Kinect mampu mendeteksi posisi kedalaman aktor dan pose aktor dengan baik. Jarak aktor dari kedua kemera yaitu $\pm 250-300 \mathrm{~cm}$. 


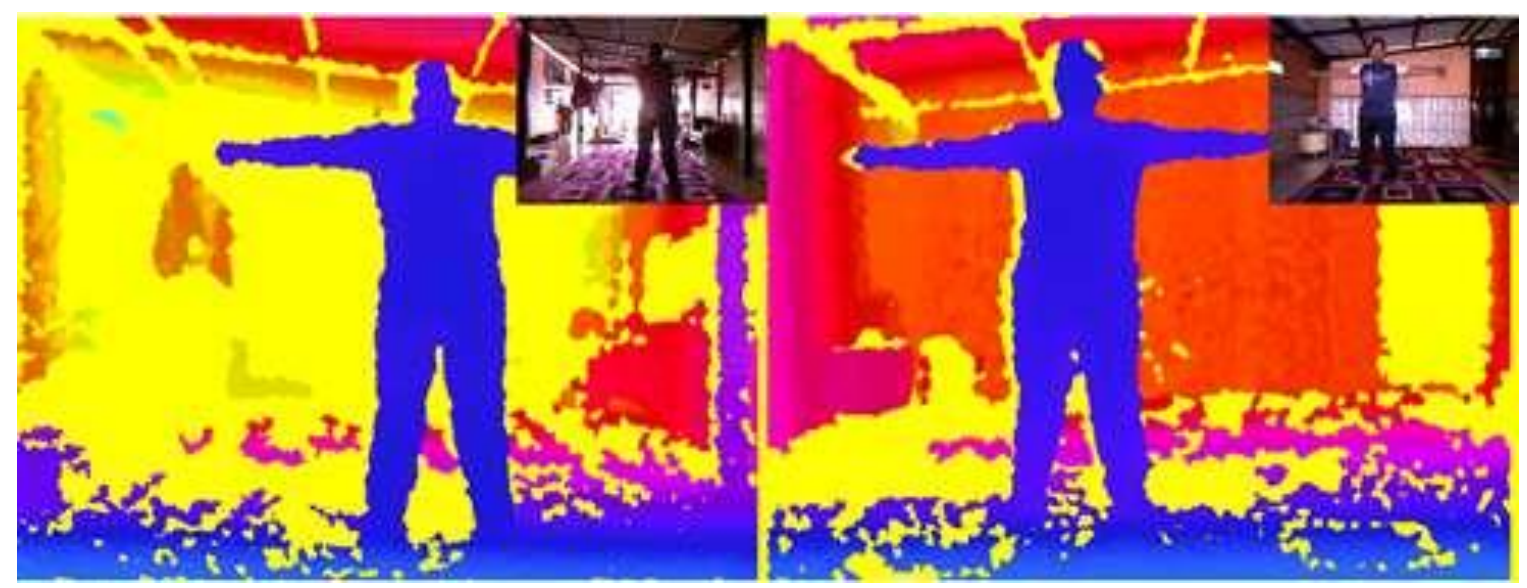

Gambar 5 Posisi Kamera Kinect Dengan Sudut $180^{\circ}$

Pada Gambar 5 kamera Kinect mampu mendeteksi posisi kedalaman aktor dan pose aktor dengan baik. Jarak aktor dari kedua kamera Kinect yaitu berada di $\pm 250 \mathrm{~cm}$ dari depan kamera.

\subsection{Pengujian Hasil Gerakan Aktor Terhadap Posisi Kamera Kinect}

Posisi kamera Kinect memiliki perbedaan hasil motion capture[3]-[5], [8]. Pada posisi kamera Kinect membentuk sudut $\mathrm{V} 60-90^{\circ}$ (lihat gambar 4), terdapat gerakan yang tidak akurat ketika aktor sedang melakukan gerakan yang membuat 2 buah bone saling menempel, salah satu contoh adalah gerakan ketika kaki rapat kemudian aktor berputar, maka bone salah satu dari kaki tersebut tidak dapat dilacak oleh kamera Kinect[9].

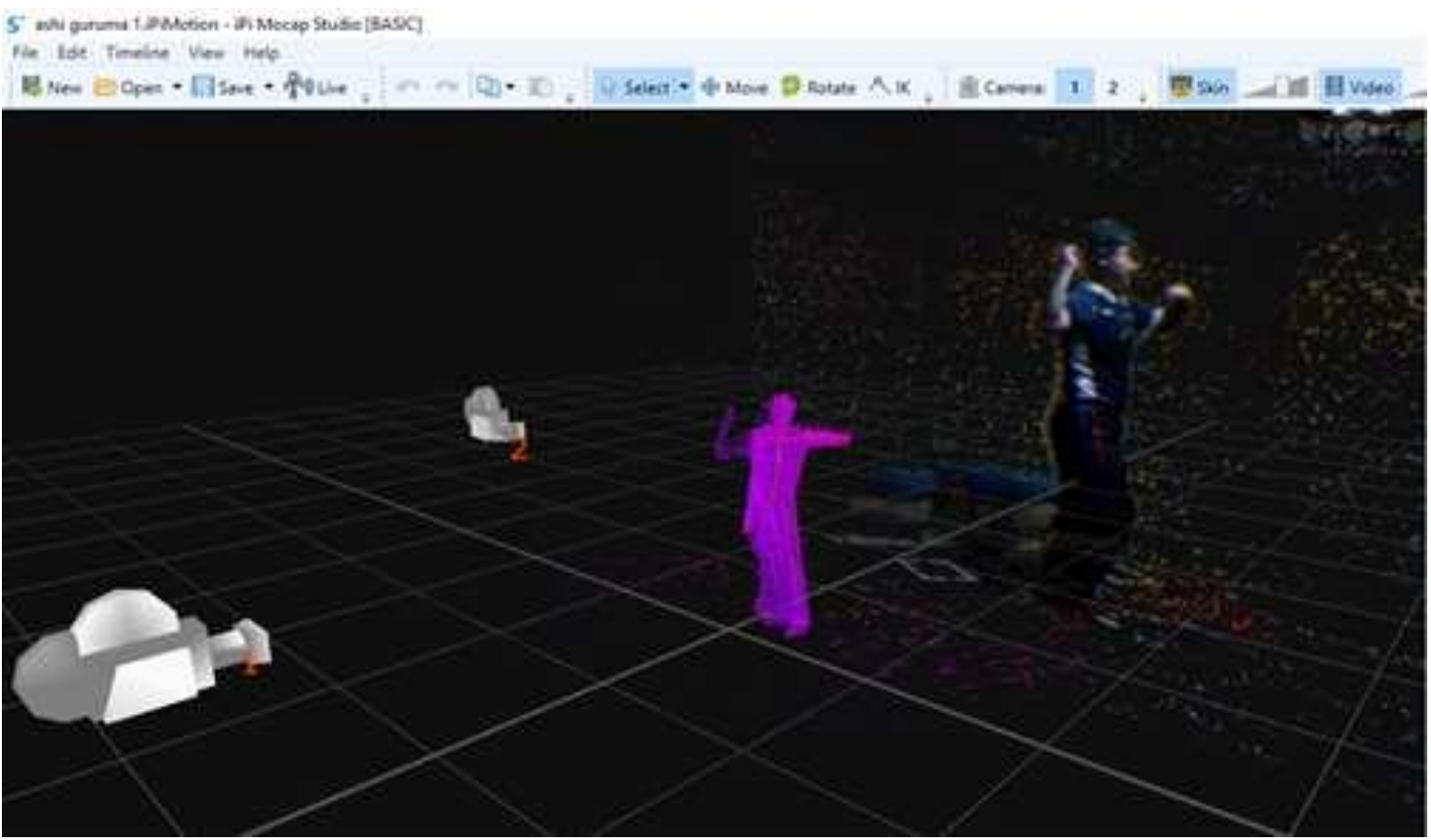

Gambar 6 Kesalahan Bone Saat Gerakan Membanting

Pada pengujian dengan posisi kamera Kinect $180^{\circ}$, gerakan dapat ditracking dengan akurat dan sedikit kesalahan deteksi bone. 


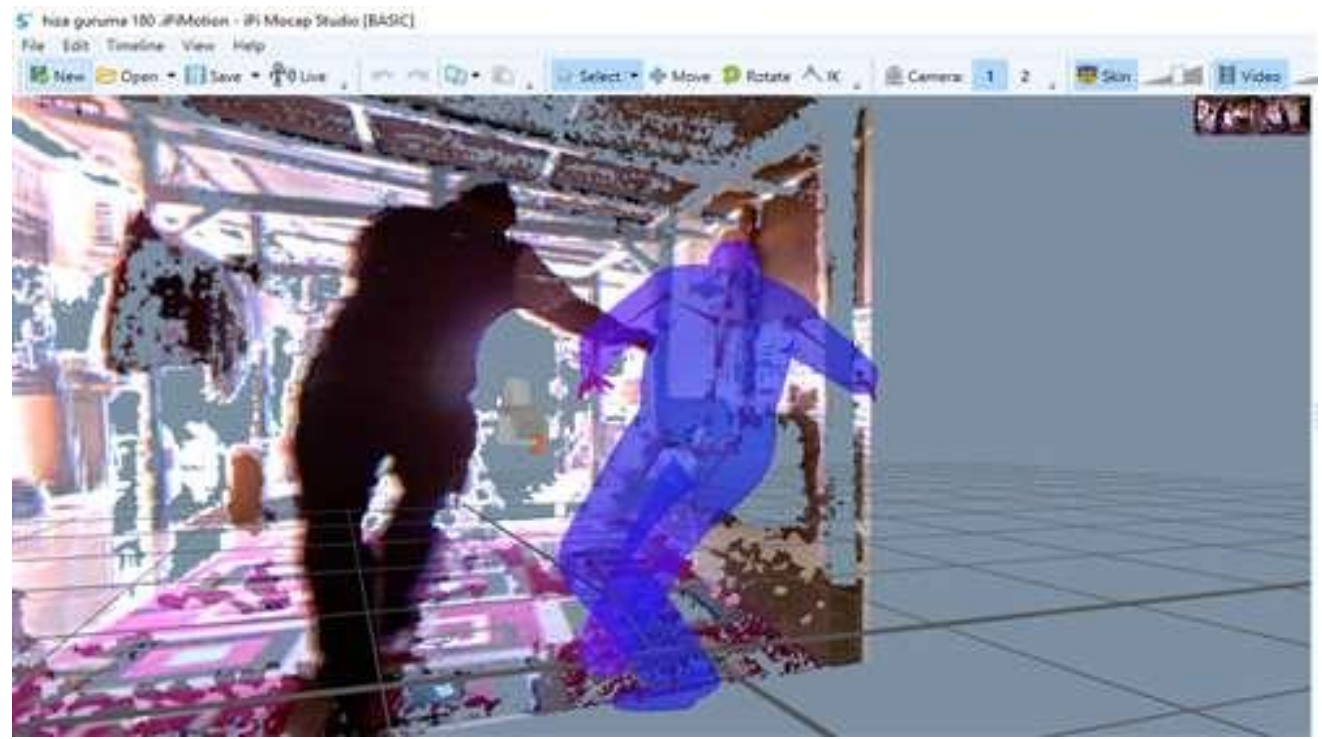

\subsection{Penerapan Hasil Animasi Pada Karakter 3D}

Gambar 7 Bone Pada Saat Posisi Membanting

Animasi yang telah di ekspor diterapkan pada karakter 3D atlet Judo. Pada gambar 8 terlihat karakter berhasil melakukan gerakan membanting[10]. Hasil animasi 6 gerakan Judo yang telah dibuat dengan posisi kamera berada di depan dan dibelakang aktor berjalan dengan baik pada model 3D[2], [11]-[15].

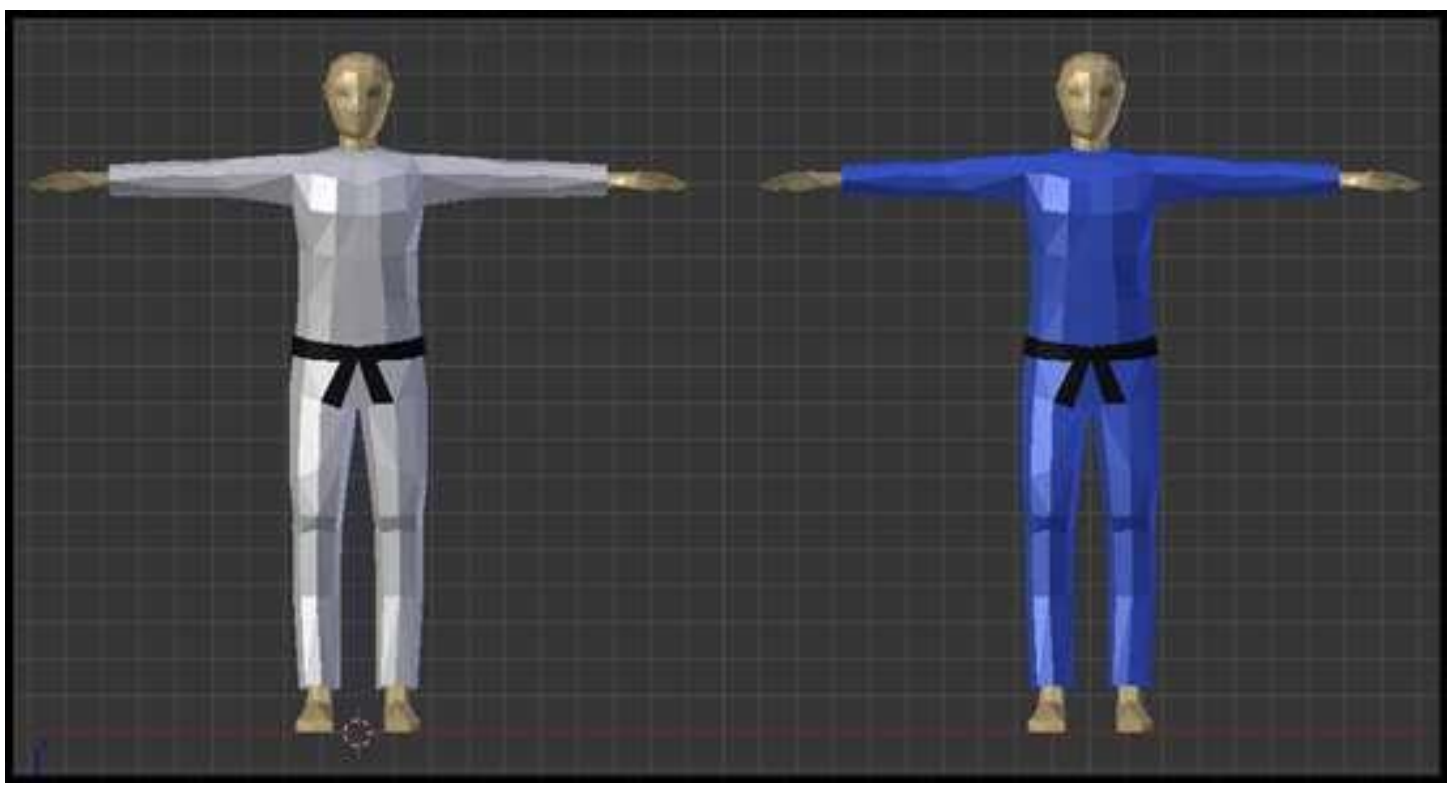

\section{Kesimpulan}

Gambar 8 Hasil Karakter 3D

Kinect sebagai alat untuk motion capture tanpa marker memudahkan dan membantu animator dalam membuat gerakan animasi yang hampir menyerupai gerakan asli. Pada Tugas Akhir ini terdapat kelemahan pada kamera Kinect v1 dengan penempatan posisi 60 - 90 terhadap aktor yaitu tidak akuratnya beberapa gerakan, seperti gerakan memutar pinggang, pinggul, dan saat bone menempel. Pada penempatan kamera Kinect v1 yang diposisikan didepan dan belakang aktor, hasil dari gerakan yang terekam lebih akurat dikarenakan kedua kamera saling menutupi ketidak akuratan dari kamera lain.

Hasil mocap juga bisa dipengaruhi oleh bentuk aktor, misal pada gerakan membanting, aktor A dan aktor B sama-sama melakukan gerakan membanting tetapi hasil animasi yang dihasilkan akan berbeda.

REPOSITOR, Vol. 2, No. 10, Oktober 2020, Pp. 1429-1435 


\section{Saran}

Beberapa saran untuk penelitian selanjutnya agar hasil animasi yang diperoleh menjadi lebih baik yaitu :

1. Pemilihan aktor yang tepat dalam melakukan perekaman gerakan agar hasil yang didapat lebih akurat pada gerakan.

2. Menggunakan kamera Kinect versi 2 karena pada versi 2 noise lebih sedikit dan dengan akurasi yang lebih dari kinect versi 1 . Kemudian untuk meminimalisir kesalahan letak bone, jumlah dan letak Kinect juga perlu ditambah, sehingga mendapatkan hasil recording gerakan yang lebih detail.

\section{Referensi}

[1] I. Fernandez and Ibis, Macromedia Flash Animation and Cartooning: A Creative Guide. McGraw-Hill/Osborne, 2002.

[2] L. Larson and S. K. Semwal, "Creating 3D avatars from artistic drawing for VR and games applications," FTC 2016 - Proc. Futur. Technol. Conf., no. December, pp. 1094-1099, 2017, doi: 10.1109/FTC.2016.7821739.

[3] D. Li, C. Sun, F. Hu, D. Zang, L. Wang, and M. Zhang, "Real-time performance-driven facial animation with 3ds Max and Kinect," 2013 3rd Int. Conf. Consum. Electron. Commun. Networks, CECNet 2013 - Proc., pp. 473-476, 2013, doi: 10.1109/CECNet.2013.6703372.

[4] F. Schlagenhauf, P. P. Sahoo, and W. Singhose, "Comparison of single-kinect and dualkinect motion capture of upper-body joint tracking," 2017 Asian Control Conf. ASCC 2017, vol. 2018-Janua, pp. 256-261, 2018, doi: 10.1109/ASCC.2017.8287176.

[5] T. B. Akinjala, R. Agada, and J. Yan, "Animating human movement \& gestures on an agent using Microsoft kinect," Proc. - 2016 IEEE Int. Symp. Multimedia, ISM 2016, pp. 369-374, 2017, doi: 10.1109/ISM.2016.3.

[6] K. Yang and J. Jie, "The designing of training simulation system based on unity 3D," Proc. - 4th Int. Conf. Intell. Comput. Technol. Autom. ICICTA 2011, vol. 1, pp. 976-978, 2011, doi: 10.1109/ICICTA.2011.245.

[7] E. Franchini, F. B. Del Vecchio, K. A. Matsushigue, and G. G. Artioli, "Physiological profiles of elite judo athletes," Sport. Med., vol. 41, no. 2, pp. 147-166, 2011, doi: 10.2165/11538580-000000000-00000.

[8] Y. Kuang, X. Bai, and X. Zhou, "A study of camera application methods in the unity 3D," 13th Int. Conf. Comput. Sci. Educ. ICCSE 2018, no. Iccse, pp. 608-610, 2018, doi: 10.1109/ICCSE.2018.8468718.

[9] J. Tong, J. Zhou, L. Liu, and Z. Pan, "Scanning 3d full human bodies using kinects," IEEE Trans., 2012.

[10] S. Corraza and E. Gambretto, "Automatic generation of 3D character animation from 3D meshes," vol. 2, no. 12, 2014.

[11] P. Smith, T. P. Hartley, and Q. H. Mehdi, "C\# interpreter and unity 3D for educational programming games," Proc. CGAMES 2013 USA - 18th Int. Conf. Comput. Games Al, Animat. Mobile, Interact. Multimedia, Educ. Serious Games, pp. 41-47, 2013, doi: 10.1109/CGames.2013.6632602.

[12] G. Amaral et al., "Animation Setup Transfer for 3D Characters," J. Petrol., vol. 369, no. 1, pp. 1689-1699, 2013, doi: 10.1017/CBO9781107415324.004.

[13] M. Makinen, "Optimizing topology for a game Character," 2018.

[14] N. Harshfield, D. J. Chang, and Rammohan, "A Unity 3D framework for algorithm animation," Proc. CGAMES 2015 USA - 20th Int. Conf. Comput. Games Al, Animat. Mobile, Interact. Multimedia, Educ. Serious Games, pp. 50-56, 2015, doi: 10.1109/CGames.2015.7272955.

[15] T. Nguyen, G. Reitmayr, and D. Schmalstieg, "Structural Modeling from Depth Images," IEEE Trans. Vis. Comput. Graph., vol. 21, no. 11, pp. 1230-1240, 2015, doi: 10.1109/TVCG.2015.2459831. 